\title{
A Case of Retropharyngeal Huge Lipoma Causing Dysphagia
}

\author{
Ki Wan Park ${ }^{1,2}$, Jin Man Kim ${ }^{3}$, Bon Seok Koo ${ }^{1,2}$, and Jae Won Chang ${ }^{1,2}$ \\ ${ }^{1}$ Departments of Otolaryngology-Head and Neck Surgery, ${ }^{2}$ Research Institute for Medical Science, ${ }^{3}$ Pathology, \\ Chungnam National University College of Medicine, Daejeon, Korea
}

\author{
삼킴장애를 유발하는 후인두 거대지방종 1예 \\ 박기완 ${ }^{1,2} \cdot$ 김진만 $^{3} \cdot$ 구본석 ${ }^{1,2} \cdot$ 장재원 ${ }^{1,2}$ \\ 충남대학교 의과대학 이비인후-두경부외과학교실, ${ }^{1}$ 의학연구소, ${ }^{2}$ 병리학교실 ${ }^{3}$
}

\author{
Received February 15, 2017 \\ Revised April 7, 2017 \\ Accepted April 10, 2017 \\ Address for correspondence \\ Jae Won Chang, MD, PhD \\ Department of Otolaryngology- \\ Head and Neck Surgery, \\ Chungnam National University \\ College of Medicine, \\ 282 Munhwa-ro, Jung-gu, \\ Daejeon 35015, Korea \\ Tel $+82-42-280-8228$ \\ Fax $+82-42-253-4059$ \\ E-mail strive1005@hanmail.net
}

Lipomas of the retropharyngeal space are rare, and they do not cause symptoms until they reach a large size. Although retropharyngeal lipoma is an uncommon entity, several reports have appeared about it in the literature, where the treatment has routinely been surgical excision. We present a case of huge lipoma of the retropharyngeal space. It extended from the oropharynx to the inferior portion of thyroid gland, causing symptoms of globus and dysphagia in a 74-year-old male. The patient had multiple medical problems and had been on anticoagulants, so we approached the mass via transcervical incision. After a complete surgical resection, all the symptoms of the patient improved. A large retropharyngeal lipoma could also be differentially diagnosed as a laryngopharyngeal mass presenting symptoms of globus and dysphagia.

Korean J Otorhinolaryngol-Head Neck Surg 2018;61(10):552-6

Key Words Dysphagia $\cdot$ Lipoma $\cdot$ Retropharyngeal space.

\section{서 론}

지방종은 중간엽 세포에서 기원하는 가장 흔한 양성종양으 로, ${ }^{1)}$ 전신에 발생할 수 있지만 약 13 15\%는 두경부에서 발생 하는 것으로 보고되며, 특히 후경부삼각(posterior neck triangle)의 피하조직에서 가장 흔하게 발생하는 것으로 알려져 있다. ${ }^{2)}$ 그러나 지방종의 인두 발생은 매우 드물게 보고되었으 며, 특히 후인두 공간에 발생한 지방종은 전 세계적으로 현재 까지 30여 개의 증례보고만이 있다.3) 해부학적 위치와 크기에 따라서 이물감, 연하곤란, 쉰 목소리, 코골이 혹은 수면무호흡 등 다양한 증상이 동반될 수 있다. 하지만 천천히 자라는 지 방종의 특성으로 인해 후인두 공간의 지방종은 상당한 크기

This is an Open Access article distributed under the terms of the Creative Commons Attribution Non-Commercial License (https://creativecommons.org/licenses/by-nc/4.0) which permits unrestricted non-commercial use, distribution, and reproduction in any medium, provided the original work is properly cited.
가 될 때까지 일반적으로 증상이 없고, 진단 당시 큰 경우가 많다. ${ }^{4}$

후인두 공간에는 지방종 외에도 새열낭종, 신경초종, 혈관 종 등의 양성종양과, 지방육종, 사르코이드증, 림프종, 전이성 종양 등의 악성종양 또한 발생할 수 있다.,6)

저자들은 다른 증상 없이 인두이물감 및 연하곤란으로 내 원한 74세 남자 환자에서 후인두 공간에 발생한 거대지방종 을 일측 경부 접근법을 통해 성공적으로 제거하여 문헌고찰 과 함께 보고하고자 한다.

\section{증 례}

74세 남자가 수년 전부터 시작된 인두이물감과 수개월 전부 터 시작된 연하곤란을 증상으로 내원하였다. 과거력상 대동맥 판막역류로 항응고제와 고혈압 약을 복용 중이었으며, 만성 
신부전으로 혈액투석치료를 받고 있었다. 음주력은 주 1 회 소 주 0.5 병 정도였고, 흡연력은 없었다. 초진 당시 환자 우측 측
경부 전체에 걸쳐 미만성의 종물이 촉지되었다. 굴곡형 후두 내시경 소견에서 우측 인두후벽을 전방으로 전위시키는 부드

Fig. 1. Preoperative endoscopic finding revealed protruding mass (white arrow) in the posterior pharyngeal wall (A). Coronal image of contrast enhanced neck CT demonstrating about $12.5 \times 9.2 \mathrm{~cm}$ retropharyngeal mass (B). The mass extended to bilateral lateral neck space lateralizing right side carotid artery and internal jugular vein on axial CT image (C). The mass protruded to posterior pharyngeal wall and covered right side arytenoid cartilage on axial CT image (white arrow, D).
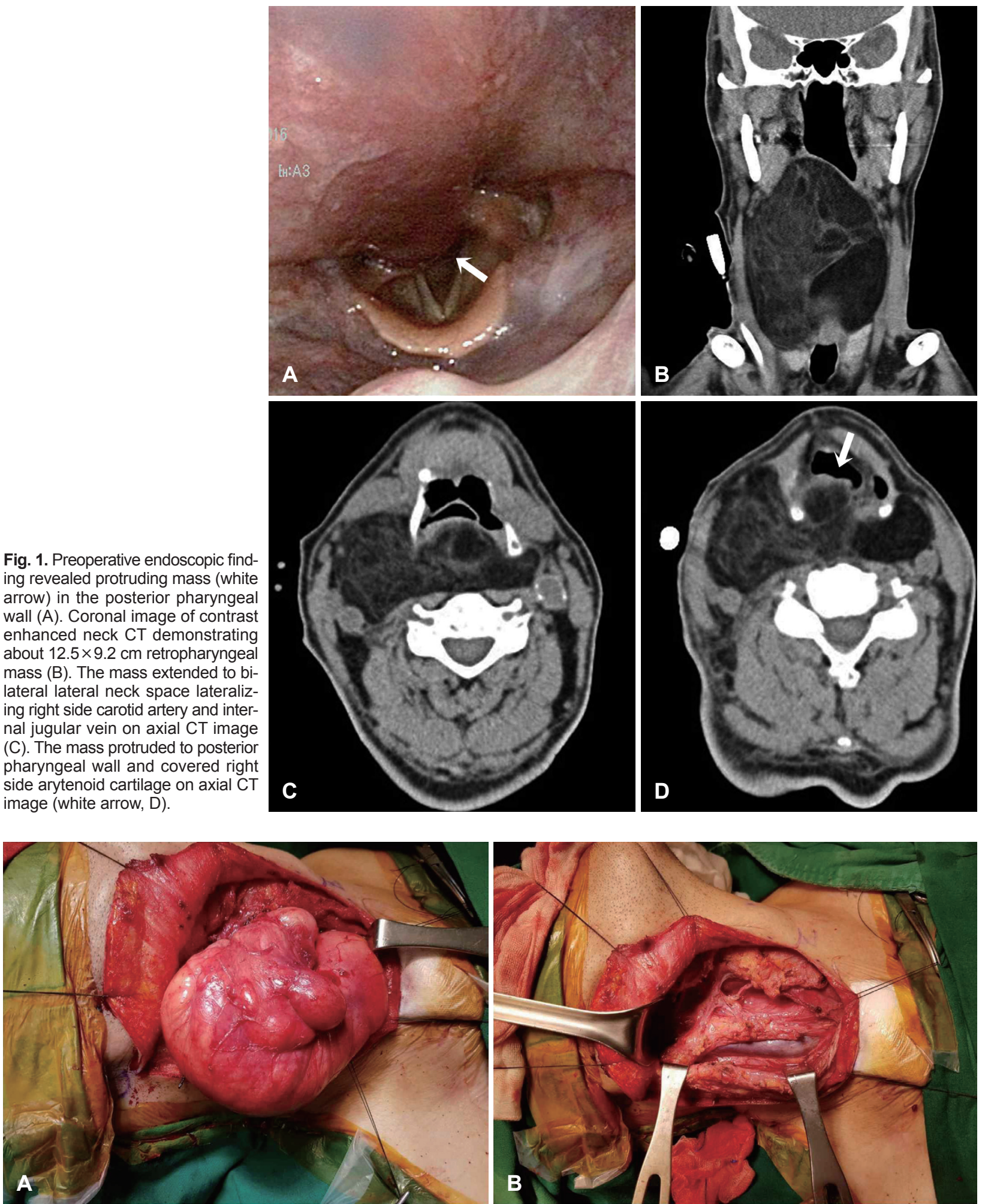

Fig. 2. Intraoperative photograph. After careful blunt dissection, whole well-capsulated lipoma including mass extended to contralateral neck was extracted without damage of great vessels or cranial nerves (A). After en-bloc resection of huge lipoma, lateralized carotid artery and internal jugular vein were lead back (B). 

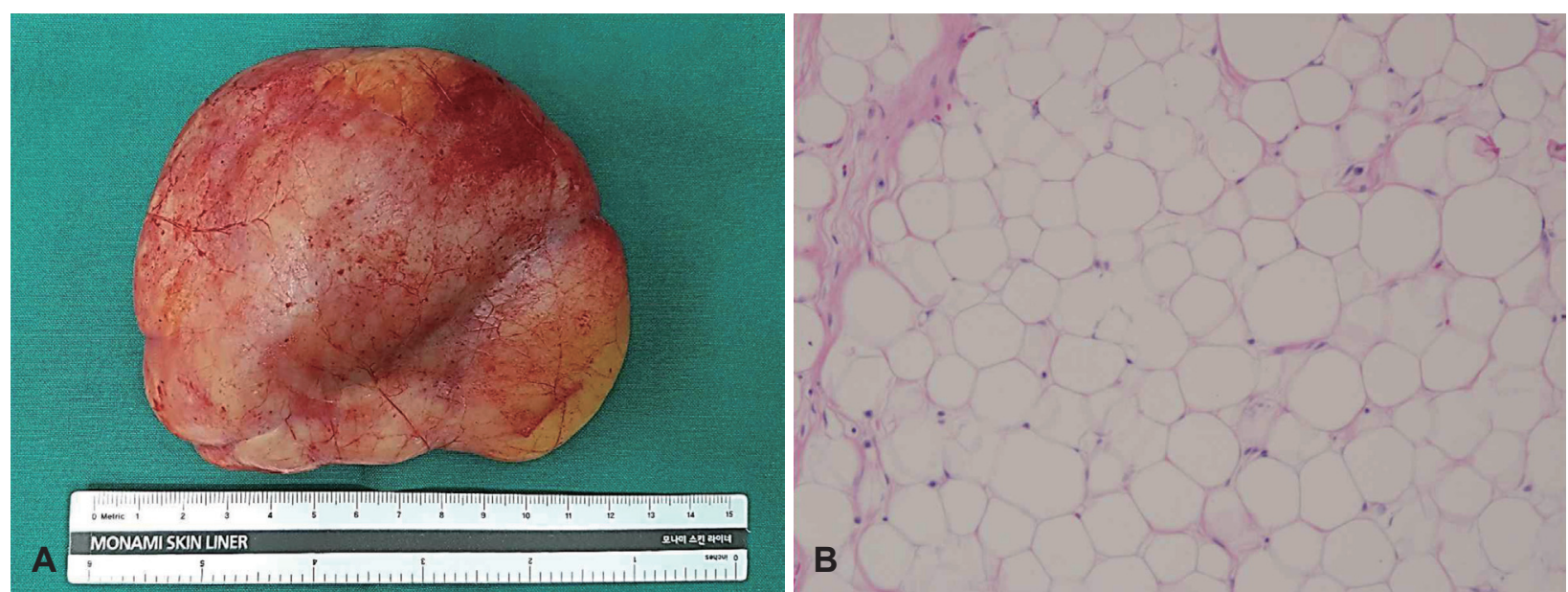

Fig. 3. Macroscopic view of lipoma. Well-encapsulated lipoma measured $12.5 \times 9.2 \times 5.6 \mathrm{~cm}$ in size (A). Histopathological finding showing the mature adipocytes with clear cytoplasm and eccentric nuclei (H\&E, $\times 400)(B)$.

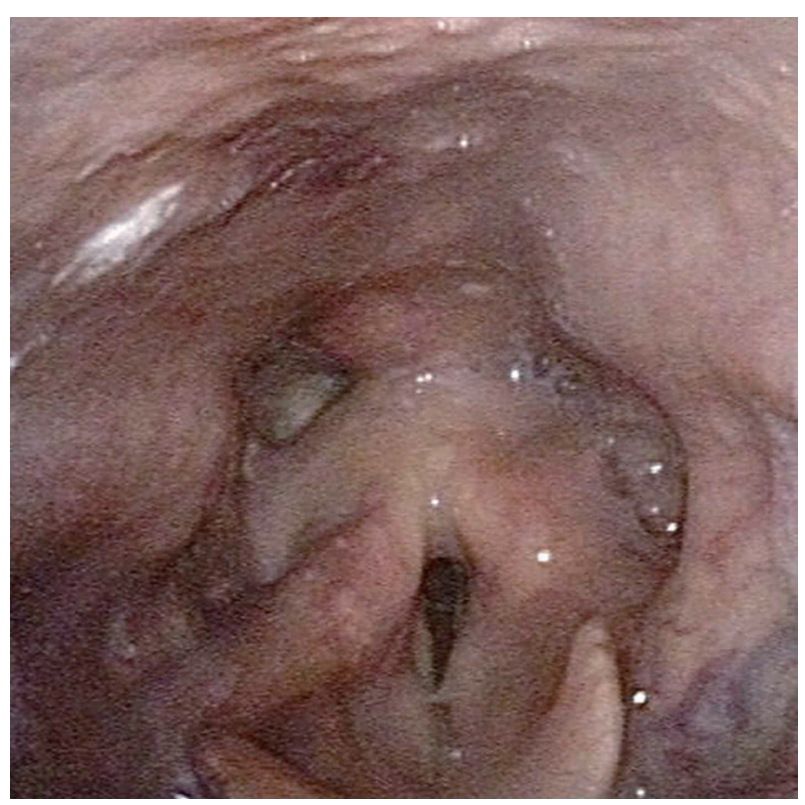

Fig. 4. Postoperative one month. Endoscopic finding showed that the mass was completely removed and posterior pharyngeal wall was normalized.

러운 점막하 종물이 관찰되었고, 이로 인하여 후두 내강이 좁 아져 있었다. 종물로 인하여 우측 피열연골을 관찰하기 어려 웠으나, 성대의 움직임은 정상이었다(Fig. $1 \mathrm{~A}$ ). 경부 전산화단 층촬영에서 약 $12 \times 9 \times 5 \mathrm{~cm}$ 크기의 경계가 명확하고 균질한, 저밀도 소견의 종물이 후인두 공간을 채우고 있었다. 이는 양 측 경동맥초를 외측으로 전위시키면서 양측 목 공간으로 확장 되어 있었으며, 특히 우측은 흥쇄유골근을 외측으로, 악하선 을 앞쪽으로 전위시킬 정도로 확장되어 있었다. 종물의 상연 은 구인두, 하연은 갑상선의 아래쪽 경계까지 확장되어 있었다 (Fig. 1B, C, and D). 초음파 유도 중심생검을 시행하여 지방 종으로 진단하였다. 기관절개를 통한 전신마취하에 우측 경
부에 하키스틱 절개를 시행한 뒤 우측 흥쇄유돌근의 전연을 따라 흥쇄유돌근과 흥골설골근 사이의 근막을 절개하자 피 낭형성된 황색 연부 종물을 관찰할 수 있었다. 종물의 피막을 따라서 경동맥초와 척추전근막(prevertebral fascia)을 박리하 였다. 후인두의 종물을 박리한 후 둔한 박리(blunt dissection) 를 계속하여 좌측 경부로 확장된 종물도 어려움 없이 박리하 여 피막으로 둘러싸인 연부종물을 완전 적출하였다(Figs. 2 and $3 \mathrm{~A})$. 술 후 환자는 특별한 합병증이 없었고, 조직병리검 사에서 투명한 세포질과 편측된 핵을 특징으로 하는 성숙지 방세포와 격막을 형성하는 섬유 조직이 관찰되어 지방종으로 확진되었다(Fig. 3B). 수술 후 10 일째 기관절개봉합술 후 퇴 원하였으며 술 후 1 개월에 시행한 연성후두내시경상 전위되 었던 인두후벽이 완전히 회복되었다(Fig. 4). 연하곤란 호전을 평가하기 위해 술 후 25일에 시행한 비디오 투시 연하검사에 서 미국언어청각협회 연하척도에서 5단계로 모든 영양을 입을 통해 섭취할 수 있는 것을 확인하였다(Fig. 5).

\section{고 찰}

지방종은 지방세포로 구성된 양성종양으로 인체에 발생하 는 양성종양 중 4 5\%를 차지하며, 피막이 잘 형성되어 주위 와 경계가 뚜렷하고 서서히 성장한다. ${ }^{7)}$ 두경부에는 비교적 드 물지만, 이 경우에도 후경부의 피하에 발생하는 것이 대부분 이다. 점막하에서의 발생은 구강, 그중에서도 협부점막에 가 장 호발하며, 이는 지방조직의 분포 때문으로 생각된다. ${ }^{8)}$

증상은 지방종의 발생 위치 및 크기에 따라서 다양하지만, 대부분 상당한 크기가 될 때까지 증상이 없을 수 있다. ${ }^{2}$ 본 증 례에서도 환자는 수년 동안 인두이물감 외에는 특이증상이 없다가 수개월 전부터 연하장애가 발생한 것으로 보아, 종물 

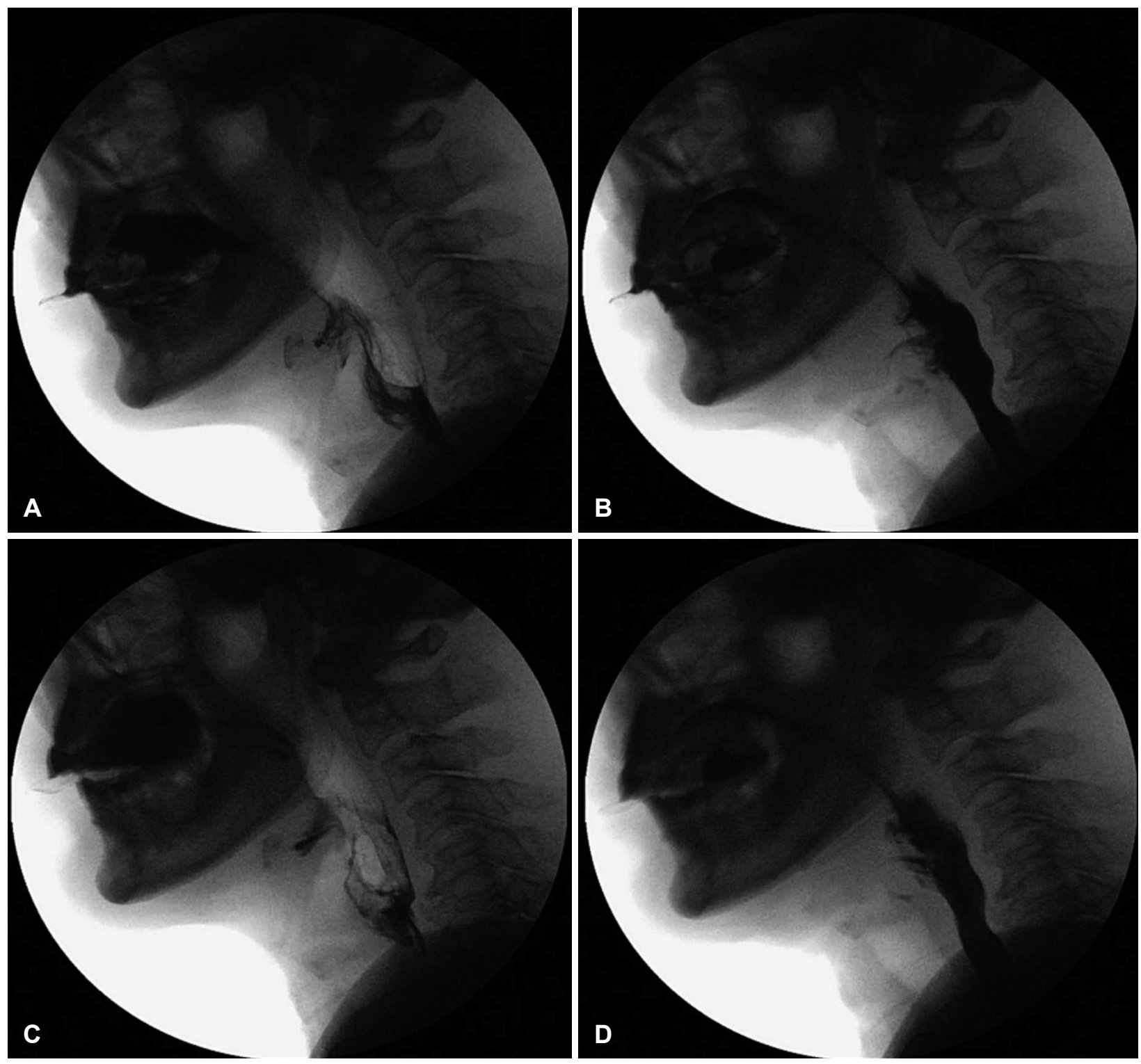

Fig. 5. Postoperative 25-day video fluoroscopic swallowing study images of the patient. Material did not enter the airway on both liquid and solid diet. Oral phase and pharyngeal phase of liquid diet (A and B). Oral phase and pharyngeal phase of solid diet (C and D). indicating normal swallowing function.

이 서서히 커져서 인두후벽을 앞으로 전위시키고, 이것이 피 열연골 상방을 압박하면서 연하장애가 유발되었을 것으로 생 각된다. 이처럼 후인두 공간에 생기는 종물은 지방종과 지방 육종이 많고, 그 외 악성종양, 전이성 림프절, 이소성 갑상선 등 이 있으며 새열낭종, 신경초종, 혈관종 등도 보고되어 철거한 두경부 신체검사와 조직검사가 필요할 수 있다. 또한 후인두 농양, 경추 골관절염에 의한 골극(osteophyte) 등과도 감별이 필요하다. ${ }^{5,6)}$ 악성종양은 비인두암이 가장 흔하며 MRI에서 $\mathrm{T} 2$ 저신호 강도와 함께 정상 점막에 비하여 조영증강이 적게 일어나는 특징을 가지고 있다. 전이성 림프절은 경계가 잘 보 이는 2 개 이상의 림프절 비대가 한쪽 후인두 공간에서 관찰
되는 것이 특징적인 것으로 알려져 있고, 신경초총은 MRI에 서 경계가 잘 지어지며 T1 저신호 강도, T2 고신호 강도를 보 이고 비균질한 가돌리늄 조영증강을 보인다. ${ }^{9)}$

진단은 영상학적 검사(CT or MRI) 등으로 추정할 수 있으 나, 술 후 적출물의 조직검사를 통해서만 최종 확진이 가능 하다. ${ }^{3)}$ 지방종은 CT에서는 경계가 명확하고 -60 -120 정도 의 Hounsfield unit을 가지는 균질한 저밀도의 종물로 보인 다. MRI에서는 T1과 T2 fast spin-echo sequence에서 고강 도신호를 보이며, 특히 종물과 척추전근육의 관계나 지방육 종의 가능성에 대한 추가 정보를 얻을 수 있다. ${ }^{3)}$ 지방육종은 일반적으로 지방종에 비하여 크고 비균질하며 성숙지방세포 
의 비율이 낮아 비지방조직에 의한 국소적인 결절과 두꺼운 격막이 관찰되는 것으로 알려져 있다. ${ }^{9-11)}$ 조직검사는 해부학 적인 위치로 인하여 대부분 술 전에 시행하기 쉽지 않지만, 본 증례처럼 종양이 경부로 확장되어 접근이 가능한 경우 시행할 수 있다. ${ }^{12)}$ 또한 영상학적 검사에서 지방종이 의심되거나 종물 의 크기가 크거나, 다발성인 경우 술 전 적극적인 세포 혹은 조직검사가 필요하다. 세침흡인검사는 분화가 잘 된 지방육 종과 양성지방종을 구별하기 어려운 것으로 알려져 있어 본 증례에서는 초음파 유도 중심생검을 시행하여 술 전에 지방 육종의 진단에 중요한 조직학적 소견인 모세혈관 비정형증식, 지방모세포(lipoblast), 이염성 간질(metachromic stroma)을 확 인하고자 하였다. 또한 환자에게 종물의 완전절제 후 최종 조 직검사를 확인하여 지방육종의 배제가 필요함을 술 전에 설 명하였다. ${ }^{12)}$

치료는 수술적인 완전절제가 원칙이다. 종물이 크고 경부의 하단까지 확장되어 내려간 경우에는 외측에서 경부접근을 하 는 경우가 대부분이며, 종물이 작고 경부의 위쪽에 있는 경우 에는 경구강접근을 시도할 수 있다. ${ }^{3)}$ 하지만 최근에 $9.4 \mathrm{~cm}$ 크기의 부인두강까지 확장된 후인두 거대지방종을 경구강으 로 제거한 증례가 보고된 바 있어 큰 지방종이라도 경우에 따라서 경구강접근 및 경구강 로봇수술을 시도해 볼 수 있을 것으로 생각한다. ${ }^{3,7)}$ 본 증례에서는 환자의 종물이 크고 경부 의 아래쪽까지 치우쳐 있었던 것 외에도, 투석을 하며 항응 고제를 복용하는 환자의 증가된 출혈 경향을 고려할 필요가 있었다. 따라서 비교적 술 후 출혈 관리가 쉽고 신속하며 종 물의 완전절제가 가능한 경부접근을 선택하여 수술을 진행 하였다.

최근에는 수면무호흡을 유발하는 후인두 지방종을 가진 고령의 환자에 대한 증례보고가 있었다. 심혈관계 질환으로 전신마취를 시행하기 어려워 수술적인 종양의 제거 없이, 양 압호흡기를 사용하여 수면무호흡이 호전되고, 매년 MRI 추 적관찰을 하면서 5 년 동안 경과를 관찰하였다. ${ }^{12)}$ 이처럼 경 우에 따라서 증상이 없는 거대 후인두지방종은 수술 없이 정 기적인 검진을 통해 경과를 관찰할 수도 있지만, 이 경우 반 드시 지방육종으로의 변성 가능성을 염두에 두고 주의 깊은 추적관찰이 필수적이다. ${ }^{12)}$ 본 증례에서는 삶의 질과 전신상 태에 영향을 줄 수 있는 연하장애가 종물의 제거 없이 호전 될 것으로 기대하기 어려우며, 추후 지방육종 변성에 대한 환자의 우려가 있었다. 또한 미용적 측면에서도 환자가 적극 적으로 수술적 제거를 원하여 수술적 치료를 진행할 수 있었 다. 후인두 종물에 대한 절제수술 이후에는 창상감염, 기도폐 쇄, 인두누공, 혈종 이외에도 해부학적 특성상 혈관과 신경 손상에 의한 합병증이 발생할 수 있다. 특히 경부접근에는 피
부 피판거상으로 발생할 수 있는 안면신경 하악변연분지 마 비, 미주신경마비, 척수부신경마비, 설하신경마비, 교감신경절 손상에 의한 호너 증후군, 혈관손상 등이 나타날 수 있으며, 구 강접근에서는 상처 벌어짐, 구인두폐쇄부전증 등이 발생할 수 있어 수술 전 환자와 보호자에게 충분한 설명이 필요하다. ${ }^{13,14)}$

저자들은 증례를 통해 연하장애를 호소하는 환자에서 인 두후벽을 앞으로 전위시키는 부드러운 종물이 있을 경우 후인 두 지방종 혹은 지방육종의 가능성도 염두에 두어야 한다는 교훈을 얻을 수 있었다. 매우 드문 증례로 아직은 분석할 자 료가 부족하지만 추후 연구를 통해 후인두 지방종과 지방육 종의 임상적 차이, 거대지방종 경과관찰 시 지방육종으로의 악성화 비율 등에 대한 연구가 필요할 것으로 사료된다.

\section{REFERENCES}

1) Jungehülsing M, Fischbach R, Pototschnig C, Eckel HE, Damm M. Rare benign tumors: laryngeal and hypopharyngeal lipomata. Ann Otol Rhinol Laryngol 2000;109(3):301-5.

2) Yoshihara T, Kawano K, Mita N. Retropharyngeal lipoma causing severe dysphagia and dyspnea. J Otolaryngol 1998;27(6):363-6.

3) Chua DY, Lim MY, Teo DT, Hwang SY. Retropharyngeal lipoma with parapharyngeal extension: is transoral excision possible? Singapore Med J 2013;54(9):e176-8.

4) Aydin U, Karakoc O, Binar M, Arslan F, Gerek M. Intraoral excision of a huge retropharyngeal lipoma causing dysphagia and obstructive sleep apnea. Braz J Otorhinolaryngol 2016 Nov 17 [Epub ahead of print]. https://doi.org/10.1016/j.bjorl.2016.10.011.

5) Righini CA, Atallah I. A retropharyngeal mass. Diagnosis: Antoni A type schwannoma. Eur Ann Otorhinolaryngol Head Neck Dis 2015;132(1):57-8.

6) Kodiyan J, Rudman JR, Rosow DE, Thomas GR. Lipoma and liposarcoma of the larynx: case reports and literature review. Am J Otolaryngol 2015;36(4):611-5.

7) De Vincentiis M, Greco A, Mascelli A, Soldo P, Zambetti G. Lipoma of the larynx: a case report. Acta Otorhinolaryngol Ital 2010;30(1): 58-63.

8) Choi EC, Kwon OH, Kim ES, Kim CK. Lipoma of the deep neck space. Korean J Otorhinolaryngol-Head Neck Surg 1997;40(1):136-40.

9) Debnam JM, Guha-Thakurta N. Retropharyngeal and prevertebral spaces: anatomic imaging and diagnosis. Otolaryngol Clin North Am 2012;45(6):1293-310.

10) Thornhill RE, Golfam M, Sheikh A, Cron GO, White EA, Werier J, et al. Differentiation of lipoma from liposarcoma on MRI using texture and shape analysis. Acad Radiol 2014;21(9):1185-94.

11) He JG, Jiang H, Yang BB, Lin PF. Liposarcoma of the retropharyngeal space with rapidly worsening dyspnea: a case report and review of the literature. Oncol Lett 2013;5(6):1939-42.

12) Hockstein NG, Anderson TA, Moonis G, Gustafson KS, Mirza N. Retropharyngeal lipoma causing obstructive sleep apnea: case report including five-year follow-up. Laryngoscope 2002;112(9): 1603-5.

13) Cho KJ. Surgical approach for parapharyngeal space tumor: transcervlcal approach. In: Lee KD, editor. Atlas of thyroid-head \& neck surgery. 1st ed. Seoul: Panmuneducation;2014. p.467-71.

14) Ryu JS. Surgical approach for parapharyngeal space tumor: transoral approach. In: Lee KD, editor. Atlas of thyroid-head \& neck surgery. 1st ed. Seoul: Panmuneducation;2014. p.481-3. 